\title{
Low recurrence rate after mini surgery outside the tendon combined with short rehabilitation in patients with midportion Achilles tendinopathy
}

This article was published in the following Dove Press journal:

Open Access Journal of Sports Medicine

17 May 2016

Number of times this article has been viewed

\author{
Håkan Alfredson ${ }^{1,2}$ \\ 'Department of Community Medicine \\ and Rehabilitation, Umeå University, \\ Umeå, Sweden; ${ }^{2}$ Institute of Sport, \\ Exercise and Health, University \\ College London Hospitals, London, \\ UK
}

Background: There is a general opinion that a structured and specific rehabilitation is needed after treatment of midportion Achilles tendinopathy to minimize recurrence of the condition. There is sparse knowledge about the recurrence rates in large patient materials after specific treatments for midportion Achilles tendinopathy.

Aim: This study aimed to investigate the recurrence rates in a large number of patients with chronic painful midportion Achilles tendinopathy that had been surgically treated with the ultrasound (US) and Doppler (DP)-guided mini-surgical scraping technique. Postoperatively, a relatively simple rehabilitation protocol, including a range of movement exercises and gradually increased walking and biking before allowing free activity, was used.

Materials and methods: From a database, information about the recurrence rates after US + DP-guided mini-surgical scraping, performed by a single surgeon on 519 tendons with US + DP-verified chronic painful midportion Achilles tendinopathy, was obtained.

Results: Recurrence of painful midportion Achilles tendinopathy was found in 26 of $519(5 \%)$ operated tendons, 13 from women and 13 from men. In 13 tendons, a close by located plantaris tendon was extirpated during the reoperation.

Conclusion: In this large material on patients treated with US + DP-guided mini-surgical scraping for midportion Achilles tendinopathy, there were few recurrences, although only a simple and nonspecific rehabilitation protocol was used.

Keywords: Achilles midportion, ultrasound, Doppler, mini-surgical scraping technique

\section{Introduction}

Chronic painful midportion Achilles tendinopathy is well known to be a relatively common and not seldom disabling condition. ${ }^{1,2,3}$ Conservative (nonsurgical) treatment, such as eccentric calf muscle training, ${ }^{4,5}$ is a first-line treatment. Surgical treatment is instituted when conservative treatment fails and has been estimated to be needed in $\sim 25 \%$ of the patients. ${ }^{6}$ The etiology is unknown, and the condition is found among both very active and completely nonactive individuals. ${ }^{3,6-8}$ Midportion Achilles tendinopathy is most commonly seen in the middle-aged group, and metabolic factors such as high blood lipids have been suggested to be involved..$^{9,10}$

There are several different approaches for surgical treatment of midportion Achilles tendinopathy. ${ }^{11-18}$ Intratendinous approaches ${ }^{11,14-18}$ and extratendinous (outside the tendon) approaches ${ }^{12,13}$ are being used.

There is an opinion that to avoid recurrences after the treatment of midportion Achilles tendinopathy, a careful and structured rehabilitation, including exercises to restore strength and endurance in the muscle-tendon unit, is needed. ${ }^{19,20}$
Correspondence: Håkan Alfredson

Department of Community Medicine and Rehabilitation, Umeå University, S-90I 87, Umeå, Sweden

Tel +4670228 844I

Fax +4690135692

Email hakan.alfredson@umu.se 
The aim of this investigation was to study the recurrence rates after an extratendinous surgical approach, the ultrasound (US) + Doppler (DP)-guided mini-surgical scraping technique, performed on a large patient material suffering from chronic painful midportion Achilles tendinopathy.

\section{Materials and methods}

From our tendon research database (information about all patients who have undergone surgical treatment for Achilles tendinopathy), information about the recurrence rates after US + DP-guided mini-surgical scraping, performed by a single surgeon during a 10-year period on 519 patients (336 men and 183 women, mean age 47 years, range $21-76$ years) with US + DP-verified chronic painful midportion Achilles tendinopathy, was obtained. Ethical approval from Umeå University was given in order to perform follow-up studies on patients treated with the US and CD-guided scraping technique, all patients had agreed to be operated with this surgical method. No written consent was required for this study.

The clinical diagnosis of midportion Achilles tendinopathy was based on a history including $>3$ months with pain located in the Achilles midportion, together with clinical examination showing a tender thickening in the Achilles midportion.

The diagnosis was confirmed with US and color Doppler (CD) examination, showing a thickened Achilles midportion with irregular tendon structure and locally high blood flow outside and inside the regions with structural tendon changes on the ventral (deep) side of the Achilles.

Recurrence was defined as remaining or recurring similar type of pain as before the operation located in the Achilles midportion, together with high pain score on the visual analog scale and US $+\mathrm{CD}$ examination showing remaining structural tendon changes and high blood flow on the ventral side of the Achilles tendon.

The patient activity levels ranged from international elitelevel sports to no sports or recreational activity. There were 61 international elite-level sports activities, the majority representing football $(\mathrm{n}=22)$, track and field $(\mathrm{n}=17)$, and rugby $(n=11)$. The remaining 458 patients were equally distributed between recreational activity (jogging, biking, cross-country skiing) and no activity (at most walking).

\section{Surgical treatment}

A longitudinal skin incision $(1-2 \mathrm{~cm})$ was placed on the lateral (first operated 270 patients) or medial (last operated 249 patients) side of the Achilles midportion, and the tendon was carefully identified. In the regions where US + DP examinations had shown structural tendon changes and high blood flow outside the ventral side of the tendon (marked by skin markers), the tendon was completely released from the ventral soft tissues, by sharp dissection with a knife, staying close to the ventral tendon. This was followed by hemostasis, using diathermy. If a plantaris tendon was found (medial incision) invaginated into the medial Achilles or located close to the medial or ventromedial side of the Achilles midportion, it was followed and released distally and proximally, cut in both ends, and extirpated. The skin was closed by single nonresorbable sutures and bandaged from toes to below knee level.

\section{Postoperative rehabilitation}

Day 1: rest, elevated foot. Day 2: range of movement (ROM) exercises, light stretching, and short walks. Days 3-7: gradually increased walking activity - distances depending on the level of discomfort. Days 8-14: light (10-15 minutes/d on gradually increased resistance) bicycling was added. After 2-3 weeks: sutures out, gradually increased loading up to free activity after $4-5$ weeks. The nonactives focused on pain-free walking, and the patients in the other activity groups, themselves or via team physiotherapists, involved exercises needed for participation in their recreation or sport activity.

\section{Results}

Recurrence of painful midportion Achilles tendinopathy was found in 26 of 519 (5\%) operated tendons, 13 from women and 13 from men.

The majority of the recurrences were seen in nonactives $(n=18)$ and only in one international elite-level athlete.

In 13 tendons, during the reoperation, a plantaris tendon was found to be located close to the medial side of the Achilles midportion and was extirpated.

\section{Discussion}

In this investigation, we found a low recurrence rate for chronic painful midportion Achilles tendinopathy in patients treated with the mini invasive US + DP-guided surgical scraping technique, followed by a short and simple rehabilitation period.

The findings in this investigation are interesting since there is an opinion that a longer rehabilitation period, including a structured program with exercises to restore strength and endurance in the muscle-tendon unit, is needed to avoid recurrences after conservative treatment of midportion Achilles tendinopathy. ${ }^{19.20}$ How then explain the findings in our investigation showing few recurrences after mini surgery outside the Achilles midportion combined with a short and simple rehabilitation program? To the best of 
my knowledge, the statement that a longer and carefully structured rehabilitation is needed is mainly based on results from conservative treatment and surgical treatments using an intratendinous approach. ${ }^{20}$ In an older study from our group, we showed that after intratendinous revision surgery, there was significantly lower calf muscle strength on the operated compared to nonoperated side. ${ }^{11}$ The type of surgery performed might be of significant importance, and it is not unlikely that after intratendinous surgical treatment, there might be more disturbances of the muscle-tendon unit compared to the disturbances caused by the extratendinous surgical approach used for US + DP-guided mini-invasive scraping. ${ }^{12,13}$ Moreover, in the early postoperative period after intratendinous surgery, there is often a period with immobilization and off-loading of the muscle-tendon unit, while after our extratendinous surgical approach, there is no immobilization and immediate full weight-bearing loading. Future studies comparing muscle/tendon function after intra- and extratendinous surgical approaches, postoperative immobilization and no immobilization, and weight-bearing loading and no loading are needed to clarify and better understand the differences and design appropriate rehabilitation models. An interesting observation from a nonpublished study at our clinic was that testing the patients with the test battery of Silbernagel et a ${ }^{19}$ for strength and endurance after the local anesthetic injection prior to surgery (painfree patient) showed no side-to-side differences between the injured and noninjured side. This indicates that the pain might be responsible for the lower strength and endurance and that midportion tendinopathy in itself might not be associated with weakness. Pain relief might be the key to full function.

It can possibly be questioned how reliable the findings from our retrospective investigation are? With the exception of the 61 international elite-level athletes, the majority of the patients are from northern Sweden and have been involved in follow-up studies. Data from these studies include a 1-year follow-up study on 61 tendons ${ }^{21}$ and a 5 -year follow-up study on 241 tendons (submitted) and confirm the few recurrences after this surgical procedure. All Swedish patients have been informed to contact us if having a recurrence of the condition; therefore, it is likely that we should have been noticed recurrences among the patients who not have been involved in the follow-up studies. The international elite-level athletes are followed up as close as possible by trying to keep informed about participation in their sports. However, of course, we cannot be completely sure that we have missed information about recurrences in this group.
For this whole patient material, two slightly different surgical approaches were used. When the first 270 patients were operated on, the skin incision was performed on the lateral side of the Achilles midportion. At that time, there was no knowledge about the possible involvement/interference of the plantaris tendon in this condition; consequently, only the scraping procedure was done. Then after finding plantaris tendon involvement in 13 cases with recurrences, there was a change to instead use a medial skin incision allowing for evaluation of a possible plantaris tendon involvement. Consequently, when the last 249 patients were operated on, there was new knowledge about the plantaris tendon, ${ }^{22}$ and in 214 of 249 patients, there was both a scraping procedure and a plantaris tendon removal.

It was interesting to note that the majority of the recurrences happened early after surgical treatment, and only one patient was reoperated on later than 1 year after the first operation. The majority of the patients with a recurrence of the condition never got pain free after the first operation. Initially there was an improvement, but then there was again a similar type of pain in the tendon as before the operation. If we then consider that 13 patients were considered to have plantaris-related pain problems at reoperation, maybe these 13 cases would never had needed a reoperation if we at that time had been better to diagnose plantaris tendon involvement in midportion Achilles tendinopathy. The other 13 patients with a recurrence were operated with another US + CD-guided scraping procedure on the ventral side of the Achilles tendon. From this large material, including also information from the follow-up studies $(19+$ submitted $)$, it seems likely to state that most recurrences will show up within the first year. Of course, we cannot be sure that very late recurrences, later than 5-year follow-up data, do not show up.

The rehabilitation program we used was very simple, including immediate full weight-bearing loading, ROM exercises, and gradually increased walking and biking before returning to their respective Achilles tendon-loading activity. All patients were followed up the day after the operation, an US scan was performed, the bandage was changed, there was wound care information, and the patients were instructed on how to perform the ROM exercises and given a written instruction on how to proceed with walking, biking, and return to their activity. We did not use a physiotherapist for instructions. Of course, we cannot be sure that the patients themselves did not include other exercises/activities than what was recommended. For the international elite-level athletes, it is likely that they added specific exercises for 
endurance, strength, and power, qualities that are needed for their sport.

The results after this type of mini-invasive surgical treatment outside the tendon have been presented previously and are not the focus of this paper. However, it might be of interest to mention that there is a very high satisfaction rate and early return to heavy Achilles tendon-loading activities, despite only using this short and simple rehabilitation model. ${ }^{13.22}$

\section{Conclusion}

In this investigation on patients suffering from chronic painful midportion Achilles tendinopathy, surgically treated with the mini-invasive US + DP-guided scraping technique outside the tendon followed by a short and simple rehabilitation program, we found a low recurrence rate. There might be less need for longer and specially designed rehabilitation models to restore strength and endurance in the muscletendon unit after this type of surgical treatment outside the tendon combined with full weight-bearing loading and early return to full activity, compared with surgical treatments inside the tendon combined with immobilization and off-loading. For chronic painful midportion Achilles tendinopathy, surgical treatment outside the tendon seems to have advantages.

\section{Disclosure}

The author reports no conflicts of interest in this work.

\section{References}

1. Asplund CA, Best TM. Achilles tendon disorders. BMJ. 2013;346:f1262.

2. De Jonge S, Van den Berg C, de Vos RJ, et al. Incidence of midportion Achilles tendinopathy in the general population. Br J Sports Med. 2011;45(13):1026-1028.

3. Kujala UM, Sarna S, Kaprio J. Cumulative incidence of Achilles tendon rupture and tendinopathy in male former elite athletes. Clin J Sport Med. 2005;15:133-135.

4. Alfredson H, Pietilä T, Lorentzon R. Heavy-load eccentric calf muscle training for the treatment of chronic Achilles tendinosis. Am J Sports Med. 1998;26(3):360-366.

5. Kingma JJ, de Knicker R, Wittink HM, Takken T. Eccentric overload training in patients with chronic Achilles tendinopathy: a systematic review. Br J Sports Med. 2007;41:e3.
6. Lopes AD, Hespanhol Junior LC, Yeung SS, Costa LO. What are the main running related musculoskeletal injuries? A systematic review. Sports Med. 2012;42:891-905.

7. Jarvinen TAH, Kannus P, Paavola M, Jarvinen TLN, Jozsa L, Jarvinen M. Achilles tendon injuries. Curr Opin Rheumatol. 2001;13(2): 150-155.

8. Knobloch K, Yoon U, Vogt PM. Acute and overuse injuries correlated to hours of training in master running athletes. Foot Ankle Int. 2008;29(7):671-676.

9. Gaida JE, Alfredson L, Kiss ZS, Wilson AM, Alfredson H, Cook JL. Dyslipidemia in Achilles tendinopathy is characteristic of insuline resistance. Med Sci Sports Exerc. 2009;41(6):1194-1197.

10. Gaida JE, Alfredson H, Kiss ZS, Bass SL, Cook JL. Asymptomatic Achilles tendon pathology is associated with a central fat distribution in men and a peripheral fat distribution in women: a cross sectional study of 298 individuals. BMC Musculoskelet Disord. 2010;11:41.

11. Alfredson H, Pietilä T, Öhberg L, Lorentzon R. Achilles tendinosis and calf muscle strength: the effect of short-term immobilization after surgical treatment. Am J Sports Med. 1998;26:166-171.

12. Alfredson H. Midportion Achilles tendinosis and the plantaris tendon. Br J Sports Med. 2011;45:1023-1025.

13. Alfredson H. Ultrasound and Doppler-guided mini-surgery to treat midportion Achilles tendinosis: results of a large material and a randomised study comparing two scraping techniques. Br J Sports Med. 2011;45(5):407-410.

14. Leppilahti J, Orava S, Karpakka J, Takala T. Overuse injuries of the Achilles tendon. Ann Chir Gynaecol. 1991;80:202-207.

15. Leadbetter WB, Mooar PA, Lane GJ, Lee SJ. The surgical treatment of tendinitis. Clinical rationale and biologic basis. Clin Sports Med. 1992;11(4):679-712.

16. Maffuli N, Testa V, Capasso G, Bifulco G, Binfield P. Results of percutaneous longitudinal tenotomy for Achilles tendinopathy in middle- and long-distance runners. Am J Sports Med. 1997;25(6):835-840.

17. Morberg P, Jerre R, Swärd L, Karlsson J. Long-term results after surgical management of partial Achilles tendon ruptures. Scand J Med Sci Sports. 1997; 7:299-303.

18. Rolf C, Movin T. Etiology, histopathology, and outcome of surgery in achillodynia. Foot Ankle Int. 1997;18(9):565-569.

19. Silbernagel KG, Gustavsson A, Thomeé R, Karlsson J. Evaluation of lower leg function in patients with Achilles tendinopathy. Knee Surg Sports Traumatol Arthrosc. 2006;14:1207-1217.

20. Silbernagel KG, Crossley KM. A proposed return to sport program for patients with midportion Achilles tendinopathy: rationale and implementation. J Orthop Sports Phys Ther. 2015;45(11):876-886.

21. Ruergard A, Alfredson H. Major physical but also psychological effects after pain relief from surgical scraping in patients with Achilles tendinopathy - a 1-year follow-up study. Pain Stud Treat. 2014; 2:21-25.

22. Spang C, Harandi VM, Alfredson H, Forsgren S. Marked innervation but also signs of nerve degeneration in between the Achilles and plantaris tendons and presence of innervation within the plantaris tendon in midportion Achilles tendinopathy. J Musculoskelet Neuronal Interact. 2015;15:197-206.
Open Access Journal of Sports Medicine

\section{Publish your work in this journal}

Open Access Journal of Sports Medicine is an international, peer-reviewed, open access journal publishing original research, reports, reviews and commentaries on all areas of sports medicine. The manuscript management system is completely online and includes a very quick and fair peer-review system.

\section{Dovepress}

Visit http://www.dovepress.com/testimonials.php to read real quotes from published authors. 